\title{
A comparative study of non-descent vaginal hysterectomy and total laparoscopic hysterectomy
}

\author{
Vijay Kansara, Jaydeep Chaudhari*, Ajesh Desai
}

Department of Obstetrics and Gynecology, GMERS Medical College and Hospital, Sola, Ahmedabad, Gujarat, India

Received: 12 December 2019

Accepted: 06 January 2020

\section{*Correspondence:}

Dr. Jaydeep Chaudhari,

E-mail: jaydeepc83@gmail.com

Copyright: (C) the author(s), publisher and licensee Medip Academy. This is an open-access article distributed under the terms of the Creative Commons Attribution Non-Commercial License, which permits unrestricted non-commercial use, distribution, and reproduction in any medium, provided the original work is properly cited.

\begin{abstract}
Background: Hysterectomy is the second most common operation performed by the gynecologists, next only to caesarean section. Objective of the study was to compare fall in blood haemoglobin level, duration of operation, intraand post-op complications between non-descent vaginal hysterectomy and total laparoscopic hysterectomy and establish the better method for hysterectomy in non-descent uterus.

Methods: A retrospective comparative study of 90 hysterectomies was done from a period of May 2018 - April 2019 at GMERS Medical College and Hospital Sola, with 45 cases in group of non-descent vaginal hysterectomy (NDVH) and 45 in group of total laparoscopic hysterectomy (TLH). Demographic characteristics, co-morbid conditions, indications for surgery, operative time, intra- operative blood loss, post-operative analgesia requirements, postoperative hospital stay and post-operative complications were compared between both groups. Those patients having malignancy as diagnosed by Pap smear or by $\mathrm{D}$ and $\mathrm{C}$ were excluded from the study

Results: The most common age in both groups was 41-50 years. Adenomyotic uterus was the most common indication for surgery in both groups. The mean operative time in NDVH group was 45 min while it was 80 min in TLH group. $\mathrm{p}<0.001$ suggested significant difference when operative time were compared between both groups. Both groups were similar in post-operative analgesia requirement and post-operative hospital stay. Post-operative complications were similar in both groups.

Conclusions: In which way to approach the uterus shall depend upon skill of the surgeon, size and pathological nature of uterus, technology available in the hospital and preference of patient as well as surgeon.
\end{abstract}

Keywords: Laparoscopic hysterectomy, Non-descent vaginal hysterectomy

\section{INTRODUCTION}

Hysterectomy is the second most common operation performed by the Gynecologists, next only to Caesarean Section. A substantial number of women undergo hysterectomy annually and $70 \%$ of hysterectomies are performed for benign indications, including leiomyoma, adenomyosis, severe dysmenorrhea and uterine prolapsed. ${ }^{1}$ The surgical approach of hysterectomy is the most important factor responsible for postoperative morbidity. Until the present, the approaches for hysterectomies are vaginal, abdominal, laparoscopic and robotic assisted laparoscopic hysterectomy. If feasible, vaginal hysterectomy is associated with a shorter duration of hospital stay, speedier recuperation, fewer unspecified infections or febrile episodes than abdominal hysterectomy. ${ }^{2}$ Since Reich first performed laparoscopic hysterectomy (LH) in 1989, various laparoscopic techniques and instruments have been developed, resulting in the vigorous implementation of $\mathrm{LH}$, including laparoscopic-assisted vaginal hysterectomy (LAVH) and total laparoscopic hysterectomy (TLH) at present. ${ }^{3}$ 
There are several reasons for the wide-spread implementation of LH. First, LH can facilitate a better anatomical view, which has advantages over $\mathrm{VH}$ in cases of severe endometriosis or when there is a history of pelvic inflammatory disease. Second, in cases of large uterine size and for uteruses with little or no descent, $\mathrm{LH}$ simplifies the separation of the uterus from its attachment to the pelvic wall.

NDVH also gives us option of minimal invasion with better access to ligaments of uterus for surgery with less blood loss and minimal analgesic requirements postsurgery and under a relatively safe spinal anesthesia rather than general anesthesia with its associated complications. Usual limitation of vaginal hysterectomy in non-descent uterus is its size, but now for uterus with larger sizes, hysterectomy can be facilitated by bisection, myomectomy, wedge debulking and intra-myometrial coring (morcellation).

Since VH and LH are minimally invasive techniques for benign indications that are widely performed around the world, authors present a comparative study of TLH with VH for benign gynecological conditions to identify which surgical approach is superior with respect to various surgical outcomes, especially the rates of complications.

\section{METHODS}

All patients who required hysterectomy without prolapse, for benign conditions were taken into studied between the periods of May 2018 to April 2019 at GMERS Medical college and hospital, Sola. A total of 90 hysterectomies were performed for benign diseases, 45 were non-decent vaginal hysterectomies and 45 were laparoscopic hysterectomies. All the surgeries were performed by the author to avoid bias in results.

Prerequisites for vaginal route were uterine size not exceeding 16 weeks of gravid uterus, adequate vaginal access and uterine mobility. Benign ovarian cysts less than $5 \mathrm{~cm}$ in size were included. Patients with severely restricted uterine mobility, complex adnexal mass and suspicion of malignancy (as diagnosed by Pap smear or by $\mathrm{D}$ and $\mathrm{C}$ ) were excluded. Informed consent was taken from all cases. . Patients who had procedures performed in addition to the hysterectomy, such as cystocele or rectocele repair were excluded from the study.

All patients were observed minutely during pre-operative, intra operative and post-operative period for any complications. Patient demographic data, operative time (from incision to placement of the final vaginal closure suture in case of NDVH and from port placement to port removal in case of TLH), estimated blood loss, change in haemoglobin concentration between the preoperative level and the first postoperative day, and length of hospital stay (defined as the total number of in-patient hospital days excluding the day of admission) were recorded. Intraoperative and immediate postoperative complications were defined as complications occurring during surgery and within 1 week of surgery respectively.

All cases in NDVH group were done under regional anaesthesia, spinal. Uterine bisection, debulking, myomectomy or combinations of these techniques were performed when required. Data regarding age, parity, uterine size, estimated blood loss, length of operation, complications and hospital stay were analysed and evaluated.

Similarly, data were collected from 45 laparoscopic hysterectomy surgeries. All surgeries were done under general anaesthesia with standard operative techniques and similar coagulation devices.

Data from both groups were compared on basic statistical analysis methods. Factors like Intraoperative time, blood loss, post-op blood transfusion, post-op haemoglobin change and hospital stay were assessed using Chi-square tests.

\section{Inclusion criteria}

- Cases of benign diseases of the uterus mainly: fibroid and polyps, adenomyosis, endometriosis, dysfunctional uterine bleeding

- Patients not responding to medical management for at least 6 months and requiring surgical management further were selected

- Patients with age $>30$ years

- Patients with clinically uterus of less than 16 weeks size.

\section{Exclusion criteria}

- Complex adnexal cyst (or $>5 \mathrm{~cm}$ )

- Prolapsed uterus

- Restricted mobility of uterus

- Suspicion of genital malignancy.

\section{RESULTS}

Table 1 shows number of patients operated according to their parity in both the groups. Major number of patients operated were having parity between 1 to 3 .

Among total NDVH operated patients $86.66 \%$ were between para 1 to para 3 while among total TLH operated patients $84.44 \%$ were also between parity 1 to 33 .

Table 1: Comparison of demographic data in both group.

\begin{tabular}{|lll|}
\hline Parity & NDVH & TLH \\
\hline Nulliparous & $1(2.22 \%)$ & 0 \\
\hline Para 1 to Para 3 & $39(86.66 \%)$ & $38(84.44 \%)$ \\
\hline Multiparous & $5(11.11 \%)$ & $7(15.55 \%)$ \\
\hline
\end{tabular}


Table 2: Distribution of hysterectomies according to their cause.

\begin{tabular}{|lll|}
\hline Indication & NDVH & TLH \\
\hline Endometrial hyperplasia & $6(13.33 \%)$ & $3(6.66 \%)$ \\
\hline Fibroid uterus & $11(24.44 \%)$ & $12(26.66 \%)$ \\
\hline Adenomyosis & $22(48.88 \%)$ & $19(42.22 \%)$ \\
\hline Postmenopausal bleeding & $1(2.22 \%)$ & $1(2.22 \%)$ \\
\hline DUB & $5(11.11 \%)$ & $7(15.55 \%)$ \\
\hline Endometriosis & 0 & $3(6.66 \%)$ \\
\hline
\end{tabular}

Table 2 shows the indication of the hysterectomies like endometrial hyperplasia, fibroid uterus, adenomyosis, postmenopausal bleeding, DUB among which major number of patients were operated for adenomyosis in both the groups NDVH and TLH by $48.88 \%$ and $42.22 \%$ respectively followed by fibroid uterus with $24.44 \%$ and $33.33 \%$ respectively.

Table 3: Age distributions between both groups.

\begin{tabular}{|lll|}
\hline Age(years) & NDVH & TLH \\
\hline $31-40$ & $10(22.22 \%)$ & $12(26.66 \%)$ \\
\hline $41-50$ & $21(46.66 \%)$ & $25(55.55 \%)$ \\
\hline $51-60$ & $10(22.22 \%)$ & $6(13.33 \%)$ \\
\hline$>60$ & $4(8.88 \%)$ & $2(4.44 \%)$ \\
\hline
\end{tabular}

Table 3 shows that major age group undergoing hysterectomy in both type of surgery were between 41-50 years.

Table 4: Difference between associated co-morbidities.

\begin{tabular}{|lll|}
\hline Comorbidities & NDVH & TLH \\
\hline Hypertension & $8(17.77 \%)$ & $10(20 \%)$ \\
\hline Diabetes & $2(4.44 \%)$ & $3(6.66 \%)$ \\
\hline HTN and DM & $1(2.22 \%)$ & $2(4.44 \%)$ \\
\hline Asthma & 0 & 0 \\
\hline Hypothyroidism & $5(11.11 \%)$ & $3(6.66 \%)$ \\
\hline High BMI & $2(4.44 \%)$ & $6(13.33 \%)$ \\
\hline Operative details & NDVH & TLH \\
\hline $\begin{array}{l}\text { Average duration of } \\
\text { surgery (minutes) }\end{array}$ & 45 & 80 \\
\hline
\end{tabular}

There is no significant difference in associated comorbidities in both the age group. Hypertension were most commonly associated with patients in both groups.

Table 5 represents the comparisons of various parameters amongst the 2 surgeries. Significant difference was observed in the average duration of the surgeries; while TLH took $\sim 80$ minutes, NDVH took only 45 minutes (P $<0.005)$. On the other hand, intraoperative blood loss was significantly less in the TLH group than in the NDVH group (80 versus $150 \mathrm{ml}) \mathrm{P}<0.001$. Similarly, the average duration of hospital stay in the TLH group was significantly less (2.5 days) in comparison to the $\mathrm{NDVH}$ group (3.4 days). Average $\mathrm{Hb}$ changes and the requirement of post op blood transfusions were significantly less in the TLH group $(\mathrm{P}<0.001)$ as depicted in Table 6.

Table 5: Comparison of different parameters amongst the two surgeries.

\begin{tabular}{|llll|}
\hline Average blood loss $(\mathrm{ml})$ & $\mathbf{1 5 0}$ & $\mathbf{8 0}$ & $<0.001$ \\
\hline Average HB Change $(\mathrm{gm} / \mathrm{dl})$ & 0.5 & 0.56 & $<0.001$ \\
\hline $\begin{array}{l}\text { Average duration of } \\
\text { hospital stay (days) }\end{array}$ & 3.2 & 3.3 & $\begin{array}{l}\text { Not } \\
\text { significant }\end{array}$ \\
\hline $\begin{array}{l}\text { Postoperative blood } \\
\text { transfusion }(\%)\end{array}$ & 4.44 & 2.5 & $<0.001$ \\
\hline
\end{tabular}

Table 6: Comparison of different complications of the surgeries.

\begin{tabular}{|lll|}
\hline Complications & NDVH & TLH \\
\hline Intra-operative complication & & \\
\hline Excessive bleeding & $1(2.22 \%)$ & 0 \\
\hline Post-operative complication & & \\
\hline Stitch line discharge & 0 & $1(2.22 \%)$ \\
\hline UTI & $4(8.88 \%)$ & $1(2.22 \%)$ \\
\hline Abdominal distension & 0 & $1(2.22 \%)$ \\
\hline Blood reaction & 0 & 0 \\
\hline $\begin{array}{l}\text { Excessive vaginal } \\
\text { discharge }\end{array}$ & $3(6.66 \%)$ & 0 \\
\hline
\end{tabular}

Table 6 shows the comparison of post-operative complications amongst both the groups. While no major complication was observed in any patient, minor complications that were managed successfully were noted in some patients. 4 patients out of 45 in the NDVH group had symptoms of UTI, 1 patient out of 45 in the TLH group had stitch line discharge. 3 patients in the NDVH group had complaints of discharge from vault while no patients in the TLH group reported with such complaints.

Table 7: Distribution according to previous surgeries.

\begin{tabular}{|lll|}
\hline Previous surgery & NDVH & TLH \\
\hline Previous 1 CS & $2(4.44 \%)$ & $3(6.66 \%)$ \\
\hline Previous 2 CS & 0 & $3(6.66 \%)$ \\
\hline Previous myomectomy & 0 & $2(4.44 \%)$ \\
\hline
\end{tabular}

Table 7 shows the comparison of both groups according to previous surgeries patients had. In both the groups there were no major complications seen like bladder injury or ureteric injury however most of the cases with previous surgeries had undergone into total laparoscopic hysterectomy.

\section{DISCUSSION}

In the absence of uterine prolapse, most gynaecologists prefer the abdominal to vaginal route of hysterectomy. The common limitations for vaginal hysterectomy in nonprolapsed uterus include size of the uterus, nulliparity, previous pelvic surgery or lower segment caesarean 
section (LSCS), pelvic adhesions and endometriosis, last but not the least limited exposure during the learning phase of their career. ${ }^{1}$ The factors that may influence the route of hysterectomy for any surgical indication include uterine size, mobility, accessibility and pathology confined to the uterus. Multiparity, lax tissues following multiple deliveries and decreased tissue tensile strength provide comfort to vaginal surgeon even in the presence of uterine enlargement. ${ }^{2,3}$

The most common indication of hysterectomy in present study was found to be Abnormal uterine bleeding due to adenomyosis (AUB A) followed by fibroid uterus (AUB $\mathrm{L}$ ). dissimilar to the findings of Dewan $\mathrm{R}$ et al who have reported Fibroid uterus as the most common indication of Hysterectomy followed by DUB amongst benign pathologies of uterus. ${ }^{4}$

Uterine enlargement was the common contraindication for vaginal surgery. In present study, the techniques of bisection, myomectomy and morcellation were used to remove bulky uterus. Davies et al and Mazdisian et al, also resorted to these techniques. ${ }^{5,6}$

The mean duration of surgery in NDVH group was 45 min which was compared with the study done by Kalpana et al., which showed the duration of $36.7 \mathrm{~min}$.

The mean blood loss in our study was $150 \mathrm{ml}$ in NDVH group, while $100 \mathrm{ml}$ was blood loss reported by Bhadra et al. ${ }^{7}$ Post-op stay in hospital was 3 days in NDVH group in our study which was compared with the study done by Chakraborthy et al. ${ }^{8}$

But insignificant difference in the amount of intra operative blood loss and $\mathrm{Hb}$ changes post operatively were reported by Fuzayel $\mathrm{AB}$ et al, Shanthi $\mathrm{S}$ et al. ${ }^{9,10}$ In this study, the average amount of blood loss in the TLH group was found to be $80 \mathrm{ml}$ in comparison to the VH group with an average blood loss of $150 \mathrm{ml}$ and hence the difference was found to be statistically significant $(p<0.05)$ Table 6 . This finding is similar to the findings of Patel $\mathrm{R}$ et al, and Roy KK et al. ${ }^{11,12}$ Also significant difference in the drop in $\mathrm{Hb}$ levels postoperatively was observed in the study between the two groups compared which is similar to the findings of Summit RL et al. ${ }^{13}$ There were no major complications during the operative procedures in our intervention which is consistent with the findings of Chattopadhyay S et al. ${ }^{14}$

The commonest indication of hysterectomy in our study was found to be abnormal uterine bleeding due to adenomyosis (AUB A) followed by fibroid uterus (AUB L). This finding is similar to the findings of Shinde $S$ et al, and Mehta ST et al. ${ }^{16}$

\section{CONCLUSION}

As the days are passing, authors are concentrating more and more on minimal invasive surgeries thus TLH and or
NDVH have gained more importance. NDVH is better in its approach through natural orifice, faster and less expansive. In peripheral hospitals where resources are limited NDVH takes upper hand than TLH as it is more economic, takes lesser time, requires less surgical techniques in comparison to TLH.

On the other hand TLH is associated with small scar of surgery, less morbidity and less post-operative pain. TLH can be a better route of surgery in obese patients in whom NDVH may be difficult. TLH can be considered an alternative to Abdominal hysterectomy for those in whom NDVH is not feasible. TLH may be better to NDVH in terms of post-operative parameters and satisfaction, but it has significantly longer operating time and requires laparoscopic surgical skills. Recent advances in equipment, surgical techniques and training have made TLH a well-tolerated and efficient technique.

In which way to approach the uterus shall depend upon skill of the surgeon, size and pathological nature of uterus, technology available in the hospital and preference of patient as well as surgeon. In this field still there is huge space for future studies and advancement.

Funding: No funding sources

Conflict of interest: None declared

Ethical approval: The study was approved by the Institutional Ethics Committee

\section{REFERENCES}

1. Balakrishnan D, Dibyajyoti G. A comparison between non descent vaginal hysterectomy and total abdominal hysterectomy. J Clin Diagn Res. 2016;10(1):11-4.

2. Gayathri KB, Sajana G, Manjusha P. Non descent vaginal hysterectomy for benign gynaecological disease: an institutional study on safety and feasibility from South India. IOSR J Dent Med Sci. 2017;16(11):59-63.

3. Mehta K, Prakash O, Fatehpuriya DS. Comparative study of abdominal hysterectomy and vaginal hysterectomy in non descent cases - a prospective study. Int J Reprod Contracept Obstet Gynaecol. 2017;6(4):1265-70.

4. Dewan R, Agarwal S, Minocha B, Sen SK. Nondescent vaginal hysterectomy - an experience. J Obstet Gynecol India. 2004;54(4):376-8.

5. Davies A, Wizza E, Bournas N. How to increase the propor-tion of hysterectomies performed vaginally. Am J Obstet Gynaecol. 1998;179:1008-12.

6. Mazdisnian F, Kurzel RB, Coe S. Vaginal hysterectomy by uterine morcellation: effecient, nonmorbid procedure. Obstet Gynaecol. 1995;86:60-4.

7. Bhadra B, Choudary AP, Tolassaria A. Non-descent vaginal hysterectomy (NDVH): personal experiences in 158 cases. AL Ameen J Med Sci. 2011;4(1):23-7. 
8. Chakraborty S, Goswami S, Mukherjee P. Hysterectomy which route? J Obstet Gynaecol India. 2011;61(5):554-7.

9. Fuzayel AB, Bhadra B, Choudhury N, Shyam DJ. Total laparoscopic hysterectomy versus non - descent vaginal hysterectomy: an observational study. Int $\mathbf{J}$ Recent Trends Sci Tech. 2017;24(2):40-3.

10. Shanthi S, Rani SU, Arumaikannu J. Feasibility of non-descent vaginal hysterectomy (NDVH) in women with scarred uterus-our experience. Int J Clin Obst Gynaecol. 2017;1(2):76-9.

11. Patel R, Chakravarty N. Comparative study of laparoscopic hysterectomy versus vaginal hysterectomy. Int $\mathbf{J}$ Med Sci Public Health. 2014;3(3):335-7.

12. Roy KK, Goyal M, Singla S, Sharma JB, Malhotra N, Kumar S. A prospective randomised study of total laparoscopic hysterectomy, laparoscopically assisted vaginal hysterectomy and non-descent vaginal hysterectomy for treatment of benign diseases of uterus. Arch Gynecol Obset. 2011;284(4):907-12.

13. Summitt RL, Stovall TG, Lipscomb GH, Ling FW. Randomized comparison of laparoscopy-assisted vaginal hysterectomy with standard vaginal hysterectomy in an outpatient setting. Obstet Gynecol. 1992;80(6):89-92.

14. Topadhyay S, Patra KK, Halder M, Mandal A, Pal P, Bhattacharyya S. A comparative study of total laparoscopic hysterectomy and non-descent vaginal hysterectomy for treatment of benign diseases of uterus. Int J Reprod Contracept Obstet Gynecol. 2017;6(3):1109-12.

15. Shinde S, Aher G, Gavali U. Non-descent vaginal hysterectomy (NDVH): Our experience at a tertiary care centre. Indian J Basic Applied Med Res. 2015;5(1):132-7.

16. Mehta ST, Trivedi YN, Bhalodia P. Role of nondescent vaginal hysterectomy in advancing gynaecological practice. NHL J Med Sci. 2014;3(1):55-8.

Cite this article as: Kansara V, Chaudhari J, Desai A. A comparative study of non-descent vaginal hysterectomy and total laparoscopic hysterectomy. Int J Reprod Contracept Obstet Gynecol 2020;9:77781 . 